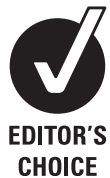

${ }^{1}$ Tampere School of Public Health, University of Tampere, Tampere, Finland ${ }^{2}$ Department of Public Health and Clinical Medicine, University of Umeå, Umeå, Sweden

\section{Correspondence to}

Pekka Virtanen, Tampere School of Public Health, University of Tampere, Tampere, Finland; pekka.j.virtanen@uta.fi

Accepted 17 October 2010 Published Online First 15 November 2010

\title{
Exposure to temporary employment and job insecurity: a longitudinal study of the health effects
}

\author{
Pekka Virtanen, ${ }^{1,2}$ Urban Janlert, ${ }^{2}$ Anne Hammarström ${ }^{2}$
}

\begin{abstract}
Objective This study analysed interactions between job insecurity and temporary employment and health. We tested the violation hypothesis (whether permanent employment increases the health risk associated with job insecurity) and the intensification hypothesis (whether temporary employment increases the health risk associated with job insecurity) in a longitudinal setting. Previous research on this topic is scarce and based on cross-sectional data.

Methods A population cohort $(n=1071)$ was surveyed at age 30 and age 42. Exposure to temporary employment during this 12-year period was elicited with a job-time matrix and measured as the score of 6-month periods. Exposure to job insecurity was measured according to the perceived threat of unemployment. Health at follow-up was assessed as optimal versus suboptimal self-rated health, sleep quality and mental health. In addition to sociodemographics and baseline health, the analyses were adjusted for exposure to unemployment, non-employment and self-employment during the 12-year period.
\end{abstract}

Results $26 \%$ of participants had been exposed to temporary employment. The effect of job insecurity on health was the same in the exposed and unexposed groups, that is the violation hypothesis was not supported. Non-significant interactions between the exposures and all health outcomes also indicated null findings regarding the intensification hypothesis.

Conclusions These findings suggest that perceived job insecurity can lead to adverse health effects in both permanent and temporary employees. Policies should aim to improve work-related well-being by reducing job insecurity. Efforts towards 'flexicurity' are important, but it is equally important to remember that a significant proportion of employees with a permanent contract experience job insecurity.

\section{BACKGROUND}

Temporary employment contracts and work insecurity are commonly considered harmful to employees, and their associations with economic, social, psychological and health-related well-being have been studied increasingly during the last two decades. ${ }^{1} 2$ This study examines their effects on various aspects of health.

A considerable number of employees with a permanent contract perceive their position in the work place or labour market to be insecure, while, conversely, all non-permanent employees do not have feelings of insecurity. It is also unclear whether temporary contract and perceived insecurity intensify one another's effects, or whether the association of insecurity with poor health is

\section{What this paper adds}

- Job insecurity may be associated with poor health more strongly among permanent than non-permanent employees, although earlier findings are inconsistent and all studies have been cross-sectional.

- This study measured exposures to job insecurity and temporary employment during a 12-year period and analysed their potential interactions with health in a longitudinal setting.

- The results of this first follow-up study in the field indicate that the adverse effects of job insecurity on health do not depend on the type of job contract.

- Policies to reduce job insecurity should be aimed at both permanent and non-permanent employees.

stronger among permanent than temporary employees. There are unwritten promises and expectations between the employer and employee according to the theory of psychological contract, ${ }^{34}$ and non-permanent employees may have more limited psychological contracts than permanent employees. Consequently, job insecurity may be associated with more comprehensive threats and more pronounced stress and adverse effects among permanent than non-permanent employees. This assumption has been called the violation hypothesis' by De Witte and Näswall. ${ }^{5}$ The intensification hypothesis, on the other hand, assumes that temporary employment and job insecurity simply intensify one another's adverse effects. So far, any interaction found between type of employment contract and degree of job insecurity has supported the violation hypothesis. The body of research is, however, relatively small.

The hypotheses have been tested mainly with respect to psychological outcomes. De Witte and Näswall ${ }^{5}$ studied job satisfaction and organisational commitment in four countries and found support for the violation hypothesis among Swedish and Belgian employees but not among those from Italy and the Netherlands. This study replicated the findings of an earlier Dutch study, and the Belgian results were replicated in a later study $^{7}$ which, however, was not able to confirm the violation hypothesis with psychological outcomes less directly related to work. ${ }^{89}$ A study of Finnish hospital employees also lends support to the violation hypothesis: among those perceiving low job insecurity the differences between permanent 
and fixed-term employees in psychological well-being were non-significant, whereas among those with high perceived insecurity a permanent contract was associated with poorer levels of all outcomes. ${ }^{10}$

As regards health, the study from the Netherlands ${ }^{6}$ analysed the effects of work status and job insecurity on mainly somatic health complaints and found no significant interaction. A Finnish study ${ }^{11}$ of municipal employees provided support for the violation hypothesis in terms of psychological distress (using the General Health Questionnaire ${ }^{12}$ ) but not self-rated general health (using a single five-option question). Belgian research ${ }^{8}$ into general health (using the SF-12 questionnaire) did not show job insecurity to be a significant moderator of the relationship between type of contract and health in a sample of industry and retail workers, while a study among Swedish hospital employees, ${ }^{13}$ utilising the General Health Questionnaire to elicit responses, yielded evidence for the violation hypothesis when permanent employees were compared with part-time and on-call employees, but not when they were compared with fixed-term employees.

Earlier research on health outcomes has provided no evidence for the intensification hypothesis, and the evidence for the violation hypothesis is inconsistent and inconclusive. The studies are, however, limited as regards the employee samples. The Swedish study concerned hospital staff, the sample in the Belgian study was recruited, with a relatively low participation rate, from a couple of workplaces in industry and retail sectors, and participants in the Finnish studies were public sector employees; only the Dutch study drew on a sample that represented a broader working population.

There is a need for further studies testing the hypotheses of violation and intensification with employee samples representing the entire labour market. Moreover, as earlier studies have been cross-sectional, it is not possible to assess whether the observed health differences are causes or consequences of job insecurity and type of job contract. The aim of the present study of the population level Northern Swedish Cohort was to test in a longitudinal setting the violation hypothesis (whether permanent employment increases the health risk associated with job insecurity) and the intensification hypothesis (whether temporary employment increases the health risk associated with job insecurity).

\section{MATERIAL AND METHODS \\ The sample}

The data came from a follow-up study that includes all pupils who in 1981 attended the last year of compulsory school (aged 16) in a middle-sized industrial town (Luleå) in the northern part of Sweden. The attrition rate has been extremely low. Of the original 1083 pupils in the sample, 93.6\% $(n=1005)$ of those still alive $(n=1071)$ participated in the follow-up in 2007. For this study, the follow-up data at age 30 (in 1995) and 42 (in 2007) were used. Data collection took place at classmate reunions and participants unable to attend the reunions received a mailed questionnaire. If data were missing, the participants were contacted by phone for supplementary information. More detailed descriptions of the method have been published elsewhere. $^{14}$

The questionnaires consisted of approximately 90 questions with a major focus on working life and on health. The questions were derived from well-known and validated questionnaires such as the Swedish National Survey on Living Conditions. ${ }^{15-17}$

The study has been approved by the Regional Ethics Review Board in Umeå.

\section{Measurement of labour market positions}

Labour market positions were elicited with a matrix that consisted of 24 columns representing half-year periods during the 12-year follow-up and 11 rows representing the positions. In responding to the question, 'During which periods have you been permanently employed or have had some type of temporary job contract or have been out of job? Mark one or more options for each spring (January to July) and autumn (August to December)'. The participants were asked to mark one or more of the options: (1) 'permanently employed', (2) 'entrepreneur', (3) 'employed on a project', (4) 'substitute', (5) 'probationary employment', (6) 'on demand worker', (7) 'seasonal worker', (8) 'temporary employee for other reasons', (9) 'unemployed', (10) 'participating in an active labour market policy measure' or (11) 'out of the labour market'. The periods with one option were recoded as 6 months, in the case of two options each was counted as 3 months, and in the case of three options each was counted as 2 months. Options 3-8 were combined into 'temporary employment', options 9 and 10 into 'unemployment', option 2 was renamed 'self-employment' and option 11 was renamed 'non-employment'. Exposure, or the total time spent in each position during the 12-year follow-up period, was then calculated in months.

\section{Measurement of job insecurity}

Both the 1995 and 2007 surveys included the question, 'How high do you assess the risk that you might become involuntarily unemployed?' with the reply options 'high', 'somewhat', 'low' and 'no'. Those replying 'high' or 'somewhat' in both surveys ( $n=152,16 \%$ ) were defined as having 'heavy' exposure to insecurity, a reply of 'low' or 'no' on both occasions ( $n=454,47 \%)$ as having 'low' exposure, and the rest of respondents ( $n=355,37 \%)$ as having 'moderate' job insecurity.

\section{Health indicators}

Self-rated general health was assessed with single three-alternative question ${ }^{15}$ and dichotomised ${ }^{18}$ as 'optimal' (reply 'good') and suboptimal (replies 'poor' and 'something in between'). Sleep problems during the past 12 months were elicited with four-alternative questions. Those replying 'never' were categorised as having 'optimal', and those replying 'every now and then', 'rather often' or 'all the time' as having 'suboptimal' sleep quality. Mental health was assessed with a version of the General Health Questionnaire consisting of six items with reply options $1-4$ on a Likert scale, where the respondents choosing 3 or 4 for more than one item were classified as 'cases' with 'suboptimal mental health'. ${ }^{2}$

\section{Background variables}

Participants' socioeconomic status was defined as blue-collar, lower white-collar or upper white-collar employee, using the occupation reported in the 2007 questionnaire and the SEI classification of Statistics Sweden. ${ }^{19}$ As the focus of this study was temporary employment, the exposures to unemployment, non-employment and self-employment were treated as background variables.

\section{Statistics}

The exposures to temporary employment, unemployment, nonemployment and self-employment were trichotomised by defining zero months as 'no' exposure and splitting the rest at median into 'moderate' and 'heavy' exposure. The prevalence of suboptimal self-rated general health, suboptimal sleep quality and suboptimal mental health was presented for the nine groups 
Table 1 Descriptive statistics of the study cohort in relation to exposure to temporary employment and job insecurity

\begin{tabular}{|c|c|c|c|c|c|c|}
\hline & \multicolumn{3}{|c|}{ Exposure to job insecurity } & \multicolumn{3}{|c|}{ Exposure to temporary employment } \\
\hline & $\begin{array}{l}\text { Low } \\
(n=447)\end{array}$ & $\begin{array}{l}\text { Moderate } \\
(n=351)\end{array}$ & $\begin{array}{l}\text { Heavy } \\
(n=148)\end{array}$ & $\begin{array}{l}\text { No } \\
(n=686)\end{array}$ & $\begin{array}{l}\text { Moderate } \\
(\mathrm{n}=158)\end{array}$ & $\begin{array}{l}\text { Heavy } \\
(n=161)\end{array}$ \\
\hline \multicolumn{7}{|l|}{ Gender } \\
\hline Men $(n=528)$ & $57 \%$ & $46 \%$ & $51 \%$ & $59 \%$ & $40 \%$ & $32 \%$ \\
\hline Women $(n=485)$ & $43 \%$ & $54 \%$ & $49 \%$ & $41 \%$ & $60 \%$ & $68 \%$ \\
\hline \multicolumn{7}{|l|}{ Socioeconomic status } \\
\hline Upper white-collar $(n=517)$ & $61 \%$ & $47 \%$ & $34 \%$ & $54 \%$ & $46 \%$ & $47 \%$ \\
\hline Lower white-collar $(n=113)$ & $11 \%$ & $15 \%$ & $18 \%$ & $13 \%$ & $20 \%$ & $10 \%$ \\
\hline Blue-collar $(n=350)$ & $28 \%$ & $38 \%$ & $49 \%$ & $33 \%$ & $34 \%$ & $43 \%$ \\
\hline \multicolumn{7}{|l|}{ Unemployment } \\
\hline No $(n=791)$ & $86 \%$ & $72 \%$ & $51 \%$ & $86 \%$ & $54 \%$ & $52 \%$ \\
\hline Moderate $(n=121)$ & $9 \%$ & $14 \%$ & $18 \%$ & $8 \%$ & $23 \%$ & $19 \%$ \\
\hline Heavy $(n=129)$ & $6 \%$ & $15 \%$ & $31 \%$ & $6 \%$ & $23 \%$ & $29 \%$ \\
\hline \multicolumn{7}{|l|}{ Non-employment } \\
\hline No $(n=802)$ & $86 \%$ & $74 \%$ & $55 \%$ & $86 \%$ & $61 \%$ & $53 \%$ \\
\hline Moderate $(n=132)$ & $9 \%$ & $15 \%$ & $19 \%$ & $8 \%$ & $20 \%$ & $26 \%$ \\
\hline Heavy $(n=107)$ & $5 \%$ & $11 \%$ & $26 \%$ & $6 \%$ & $19 \%$ & $21 \%$ \\
\hline \multicolumn{7}{|l|}{ Self-employment } \\
\hline No $(n=894)$ & $83 \%$ & $85 \%$ & $91 \%$ & $85 \%$ & $87 \%$ & $86 \%$ \\
\hline Moderate $(n=85)$ & $8 \%$ & $9 \%$ & $6 \%$ & $7 \%$ & $10 \%$ & $13 \%$ \\
\hline Heavy $(n=63)$ & $9 \%$ & $5 \%$ & $3 \%$ & $8 \%$ & $3 \%$ & $1 \%$ \\
\hline \multicolumn{7}{|l|}{ Temporary employment } \\
\hline No $(n=436)$ & $82 \%$ & $60 \%$ & $47 \%$ & & & \\
\hline Moderate $(\mathrm{n}=81)$ & $11 \%$ & $18 \%$ & $22 \%$ & & & \\
\hline Heavy $(n=78)$ & $7 \%$ & $21 \%$ & $31 \%$ & & & \\
\hline
\end{tabular}

divided according to this three-class variable and the three-class variable of exposure to job insecurity. Health differences between the groups were demonstrated by means of binary logistic regression analyses, using those with low insecurity and with no exposure to temporary employment as a reference group. The analyses were adjusted for background variables and, in order to control for health-related selection, were also adjusted for the baseline value of the outcome of interest. Next, exposures to unemployment, non-employment and selfemployment were added to the models. Finally, the hypotheses were tested by statistical significance of the interaction between job insecurity and temporary employment from fully adjusted logistic regression analyses where these two exposures were introduced as separate variables.

\section{RESULTS}

Descriptive statistics of the participants (table 1) demonstrate that exposure to temporary employment was more common in women and heavy exposure to job insecurity was more common in blue-collar employees. Job insecurity and temporary employment were associated with unemployment and non-employment but not with self-employment. As would be expected, exposure to temporary employment increased along with exposure to insecurity, but it is noteworthy that almost half of the heavy insecurity group were not exposed to temporary employment.

\section{Self-rated health}

Suboptimal self-rated general health increased with insecurity more among employees with exposure than among those with no exposure to temporary employment (table 2). These figures seem to contradict the violation hypothesis. However, the interaction of the exposures on self-rated health was non-significant $(\mathrm{p}=0.764)$

\section{Sleep quality}

The steepest increase in suboptimal sleep quality as a result of insecurity was seen among employees not exposed to temporary employment (table 3). This is in accordance with the violation hypothesis, but as the increase was also substantial in those with moderate and heavy exposure, the insecurity $\times$ temporary interaction was non-significant $(p=0.583)$.

\section{Mental health}

Insecurity also increased the prevalence of suboptimal mental health (table 4), and although the increase was somewhat

Table 2 Prevalence (\%) and OR $(95 \% \mathrm{Cl})$ for suboptimal self-rated health at the end of the 12-year follow-up period in relation to exposure to temporary employment and job insecurity

\begin{tabular}{|c|c|c|c|c|c|c|}
\hline \multirow{3}{*}{$\begin{array}{l}\text { Exposure } \\
\text { to job } \\
\text { insecurity }\end{array}$} & \multicolumn{6}{|c|}{ Exposure to temporary employment } \\
\hline & \multicolumn{2}{|c|}{$\overline{\text { No }}$} & \multicolumn{2}{|c|}{ Moderate } & \multicolumn{2}{|c|}{ Heavy } \\
\hline & $\%$ & OR (95\% Cl) & $\%$ & OR (95\% Cl) & $\%$ & OR $(95 \% \mathrm{Cl})$ \\
\hline \multicolumn{7}{|l|}{ Model 1} \\
\hline Low & 28 & 1 & 27 & $0.95(0.48$ to 1.86$)$ & 28 & $1.02(0.46$ to 2.29$)$ \\
\hline Moderate & 37 & 1.50 (1.05 to 2.17$)$ & 47 & $2.32(1.35$ to 3.98$)$ & 36 & 1.47 (0.87 to 2.49$)$ \\
\hline Heavy & 51 & $2.70(1.60$ to 4.56$)$ & 59 & $3.84(1.83$ to 8.05$)$ & 58 & 3.59 (1.90 to 6.77$)$ \\
\hline \multicolumn{7}{|l|}{ Model 2} \\
\hline Low & & 1 & & $0.98(0.49$ to 1.97$)$ & & 0.73 (0.31 to 1.73$)$ \\
\hline Moderate & & $1.42(0.97$ to 2.07$)$ & & $1.68(0.94$ to 3.02$)$ & & 1.18 (0.67 to 2.06$)$ \\
\hline Heavy & & 1.85 (1.05 to 3.26$)$ & & $2.64(1.20$ to 5.82$)$ & & $2.68(1.35$ to 5.30$)$ \\
\hline \multicolumn{7}{|l|}{ Model 3} \\
\hline Low & & 1 & & $0.87(0.42$ to 1.77$)$ & & $0.64(0.26$ to 1.53$)$ \\
\hline Moderate & & $1.37(0.93$ to 2.01$)$ & & $1.44(0.79$ to 2.65$)$ & & 0.98 (0.54 to 1.77$)$ \\
\hline Heavy & & $1.59(0.89$ to 2.86$)$ & & $2.13(0.93$ to 4.87$)$ & & 2.00 (0.98 to 4.12$)$ \\
\hline
\end{tabular}

Model 1: unadjusted.

Model 2: adjusted for gender, self-rated health at baseline and socioeconomic position Model 3: model 2 plus unemployment, non-employment and self-employment during the follow-up period. 
Table 3 Distribution (\%) and OR (95\% CI) for suboptimal sleep quality at the end of the 12-year follow-up period in relation to exposure to non-permanent employment and job insecurity

\begin{tabular}{|c|c|c|c|c|c|c|}
\hline \multirow{3}{*}{$\begin{array}{l}\text { Exposure } \\
\text { to job } \\
\text { insecurity }\end{array}$} & \multicolumn{6}{|c|}{ Exposure to temporary employment } \\
\hline & \multicolumn{2}{|l|}{ No } & \multicolumn{2}{|c|}{ Moderate } & \multicolumn{2}{|c|}{ Heavy } \\
\hline & $\%$ & OR $(95 \% \mathrm{Cl})$ & $\%$ & OR $(95 \% \mathrm{Cl})$ & $\%$ & OR $(95 \% \mathrm{Cl})$ \\
\hline \multicolumn{7}{|l|}{ Model 1} \\
\hline Low & 40 & 1 & 47 & $1.32(0.72$ to 2.40$)$ & 50 & $1.49(0.72$ to 3.07$)$ \\
\hline Moderate & 52 & $1.62(1.15$ to 2.28$)$ & 55 & 1.80 (1.05 to 3.07$)$ & 52 & 1.61 (0.98 to 2.66$)$ \\
\hline Heavy & 73 & 3.92 (2.22 to 6.92$)$ & 66 & 2.84 (1.33 to 6.07$)$ & 64 & 2.70 (1.42 to 5.15$)$ \\
\hline \multicolumn{7}{|l|}{ Model 2} \\
\hline Low & & 1 & & $1.22(0.65$ to 2.27$)$ & & $1.47(0.70$ to 3.10$)$ \\
\hline Moderate & & 1.49 (1.04 to 2.12$)$ & & 1.39 (0.79 to 2.44$)$ & & $1.33(0.79$ to 2.25$)$ \\
\hline Heavy & & 3.51 (1.95 to 6.32$)$ & & 2.36 (1.08 to 5.15$)$ & & $2.25(1.15$ to 4.40$)$ \\
\hline \multicolumn{7}{|l|}{ Model 3} \\
\hline Low & & 1 & & $1.02(0.54$ to 1.93$)$ & & 1.28 (0.60 to 2.73$)$ \\
\hline Moderate & & $1.43(1.01$ to 2.05$)$ & & $1.13(0.64$ to 2.03$)$ & & $1.04(0.60$ to 1.82$)$ \\
\hline Heavy & & 2.93 (1.60 to 5.35$)$ & & 1.68 (0.74 to 3.83$)$ & & 1.61 (0.79 to 3.28$)$ \\
\hline
\end{tabular}

Model 1: unadjusted.

Model 2: adjusted for gender, self-rated health at baseline and socioeconomic position.

Model 3: model 2 plus unemployment, non-employment and self-employment during the follow-up period.

smaller among those with exposure to temporary employment, the interaction was clearly non-significant $(p=0.967)$.

\section{DISCUSSION}

Among studies on temporary employment and job insecurity, this was the first in which the hypotheses of violation and intensification were explored in a longitudinal setting with a sample representing the entire working population. Accumulation of exposure to temporary employment and job insecurity was measured from age 30 to 42, and health was measured at the beginning and at the end of the follow-up. The effects of job insecurity on health were found to be similar among permanent and non-permanent employees. Thus, neither the violation nor the intensification hypothesis was supported.

Regarding the violation hypothesis, the finding concerning self-rated general health corresponds to previous Finnish ${ }^{11}$ and Belgian $^{7}$ studies. On the other hand, the validity of the violation hypothesis has been demonstrated in studies on mental health

Table 4 Distribution (\%) and OR (95\% Cl) for suboptimal mental health at the end of the 12-year follow-up period in relation to exposure to temporary employment and job insecurity

\begin{tabular}{|c|c|c|c|c|c|c|}
\hline \multirow{3}{*}{$\begin{array}{l}\text { Exposure } \\
\text { to job } \\
\text { insecurity }\end{array}$} & \multicolumn{6}{|c|}{ Exposure to temporary employment } \\
\hline & \multicolumn{2}{|c|}{ No } & \multicolumn{2}{|c|}{ Light } & \multicolumn{2}{|c|}{ Heavy } \\
\hline & $\%$ & OR $(95 \%$ Cl) & $\%$ & OR $(95 \% \mathrm{Cl})$ & $\%$ & OR $(95 \% \mathrm{Cl})$ \\
\hline \multicolumn{7}{|l|}{ Model 1} \\
\hline Low & 9 & 1 & 12 & 1.43 (0.57 to 3.62 ) & ) 14 & $1.64(0.54$ to 5.01$)$ \\
\hline Moderate & 13 & 1.51 (0.88 to 2.60$)$ & 20 & 2.61 (1.29 to 5.31$)$ & 21 & 2.70 (1.37 to 5.30$)$ \\
\hline Heavy & 22 & 2.90 (1.47 to 5.72 ) & ) 28 & 4.01 (1.71 to 9.40$)$ & ) 21 & $2.71(1.20$ to 6.16$)$ \\
\hline \multicolumn{7}{|l|}{ Model 2} \\
\hline Low & & 1 & & 1.40 (0.54 to 3.62$)$ & & $1.34(0.43$ to 4.21$)$ \\
\hline Moderate & & 1.30 (0.74 to 2.29 ) & & 2.05 (0.97 to 4.34$)$ & & 2.24 (1.10 to 4.58$)$ \\
\hline Heavy & & 2.16 (1.02 to 4.59$)$ & & 3.57 (1.47 to 8.69 ) & & $2.33(0.99$ to 5.51$)$ \\
\hline \multicolumn{7}{|l|}{ Model 3} \\
\hline Low & & 1 & & 1.16 (0.45 to 3.03$)$ & & $1.11(0.35$ to 3.55$)$ \\
\hline Moderate & & 1.25 (0.70 to 2.21$)$ & & $1.66(0.76$ to 3.61$)$ & & 1.67 (0.78 to 3.58$)$ \\
\hline Heavy & & 1.70 (0.77 to 3.75$)$ & & 2.44 (0.95 to 6.29$)$ & & 1.57 (0.62 to 3.96$)$ \\
\hline
\end{tabular}

Model 1: unadjusted.

Model 2: adjusted for gender, self-rated health at baseline and socioeconomic position.

Model 3: model 2 plus unemployment, non-employment and self-employment during the follow-up period. and work-related psychological well-being. ${ }^{4} 101113$ Our results regarding sleeping problems and psychological distress contradict these findings. In all, this study strengthens the impression ${ }^{7}$ that violation can be demonstrated mainly with outcomes that are linked closely or exclusively to work, such as job satisfaction, whereas it is difficult to show significant differences with multifactorial outcomes such as health. The effect sizes (Nagelkerke $\mathrm{R}^{2}$ estimates) demonstrate the nature of the outcomes: the combined exposure variable explains $8.1 \%$ of selfrated general health, $7.7 \%$ of sleep quality and $5.5 \%$ of mental health in the univariate regression analyses, in multivariate analyses (Models 3 ) the respective figures are 17.5\%,13.1\% and $10.6 \%$. One reason for the varying findings may lie in the samples; our study represented the entire working population in all sectors of the labour market.

Our study was designed to reveal causal associations between exposure to temporary employment and job insecurity and health problems. Therefore, we adjusted the analyses for baseline levels of outcomes. This procedure, however, only partly excludes reverse causality (selection into temporary employment due to poor health and job insecurity as a consequence of poor health) which may have influenced the cohort during the 12 -year follow-up. Consequently, the findings may to some degree overestimate the health effects of job insecurity and temporary employment. Moreover, interpretation of the findings is complicated by potentially differential 'healthy employee effect', or health-related exit from the labour market, of the studied nine contract-insecurity groups. Such sources of uncertainty are unavoidable in observational epidemiological follow-up settings where causality can logically occur in both directions.

Nevertheless, the follow-up design, as regards both the health variables and exposure to temporary employment and job insecurity, can be considered a strength. Another strength of this study is the high response rate which rules out a non-participation bias. As members of the cohort were all the same age, macro-economic fluctuations affected the participants at the same times in their lives. After the age of 30, the 'natural' temporary employment and insecurity that characterises entry to work life is over. Moreover, exposures to other labour market positions during the follow-up period were controlled for in the analyses.

The cohort with moderate job insecurity is heterogeneous in that most of the participants $(n=268)$ reported insecurity only at baseline, but there were also others $(n=83)$ reporting insecurity only at follow-up. They were joined together in this study because the exposure concept we adopted meant our focus was not on timing but on accumulated insecurity.

It is uncertain how correctly the job-time matrix applied in this study measured exposure to temporary employment and other labour market positions. However, preliminary results from a test-retest study where approximately 200 participants were asked to fill in the matrix again 6 months later, showed very high concordance. Some variation was seen in reports of positions for specific time periods, but when scored over the whole follow-up, the number of months in different positions was almost identical. Therefore, even if the objective history of contracts and labour market status differs from the reported history, we can be fairly sure that classification of respondents into groups with no, light and heavy exposure to temporary employment correctly reflects the true exposure gradient.

The major components of job insecurity are threat of job loss and threat of losing important job elements. ${ }^{20} 21$ The measure used in this study, that is insecurity about future employment, 
is probably more relevant and common for both permanent and fixed-term employees than threats, for example to position in the organisation or current job tasks. Moreover, earlier research has shown that threat of unemployment is associated with stress-related physiological reactions ${ }^{22}$; it is therefore particularly relevant in a study with health outcomes. Still, insecurity may depend so much on the particular employee contract that the validity and reliability of a method measuring and comparing the job insecurity of employees with different contracts cannot be guaranteed. ${ }^{23}$

The characteristics of labour markets and job insecurity are partly nation dependent. Therefore, the findings of this Swedish study should be generalised with caution. The body of research should be extended with more follow-up studies from different countries. In our cohort, about one in four individuals was exposed to temporary employment, so splitting the exposures by type of contract would have led to rather small groups and reduced the power of the statistical analyses. In future studies cohorts should be larger and selected with an eye to the heterogeneity of non-permanent employment, and more sophisticated methods to define different labour market trajectories should be developed. Such research would also contribute to more sophisticated theoretical and conceptual understanding of the psychological contract and stressful labour market experiences. Also, the results of this study do not mean that the violation hypothesis should be rejected as regards more proximal psychological outcomes.

This study emphasises that reduction in job insecurity should be a key target in policies aiming to improve work related well-being. Efforts towards 'flexicurity' ${ }^{\text {'2 }}$ are important, but it is just as important to bear in mind that a considerable proportion of employees who have permanent contracts experience job insecurity.

Funding This work was partially supported by the Umeå Centre for Global Health Research, with support from FAS, the Swedish Council for Working Life and Social Research (grant no. 2006-1512) and by the Academy of Finland (grant no. 132668).

\section{Competing interests None.}

Ethics approval This study was conducted with the approval of the Regional Ethics Review Board in Umeå.

Provenance and peer review Not commissioned; externally peer reviewed.

\section{REFERENCES}

1. Ferrie $\mathbf{J}$, Westerlund $\mathrm{H}$, Virtanen $\mathrm{M}$, et al. Flexible labor market and employee health. Scand J Work Environ Health Supplements 2008;6:98-110.
2. Cheng G, Chan D. Who suffers more from job insecurity? A meta-analytic review. Appl Psychol Int Rev 2008;37:272-303.

3. Rousseau D. Psychological contracts in organizations: understanding written and unwritten agreements. Thousand Oaks CA: Sage, 1995.

4. King J. White collar reactions to job insecurity and the role of the psychological contract: Implications of Human Resource Management. Hum Resour Manage 2000;39:79-92.

5. De Witte H, Näswall K. 'Objective' vs 'subjective' job insecurity: consequences of temporary work for job satisfaction and organizational commitment in four European countries. Econ Ind Democracy 2003;24:149-88.

6. Klein Hesselink K, van Vuuren T. Job flexibility and job insecurity: the Dutch case. Eur J Work Organ Psychol 1999:8:273-93.

7. De Cuyper N, De Witte H. Job insecurity: mediator or moderator of the relationship between type of contract and various outcomes. SA J Ind Psychol 2005;31:79-86.

8. De Cuyper $\mathbf{N}$, De Witte $\mathrm{H}$. The impact of job insecurity and contract type on attitudes, well-being and behavioural reports. J Occup Organ Psychol 2006; 79:395-409.

9. De Cuyper $\mathbf{N}$, De Witte $H$. Job insecurity among temporary versus permanent workers: Effects on job satisfaction, organizational commitment, life satisfaction and self-rated performance. Work Stress 2007;21:65-84

10. Mauno S, Kinnunen U, Mäkikangas A, et al. Psychological consequences of fixed-term employment and perceived job insecurity among health care staff. Eur J Work Organ Psychol 2005;14:209-37.

11. Virtanen P, Vahtera J, Kivimäki $\mathrm{M}$, et al. Employment security and health. J Epidemiol Community Health 2002;56:569-74.

12. Goldberg D. The detection of psychiatric illness by question. London: Oxford University Press, 1972

13. Bernhard-Oettel C, Sverke M, De Witte H. Comparing three alternative types of employment with permanent full-time work: how do employment contract and perceived job conditions relate to health complaints? Work Stress 2005:19:301-18

14. Novo M. Young and unemployed - does the trade cycle matter for health. Thesis Umeå: University of Umeå, 2000.

15. Statistics Sweden. Survey of living conditions. Stockholm: Statistics Sweden, 1980.

16. Erikson R, Ảberg R, eds. Welfare in transition. a survey of living conditions in Sweden 1968-1981. Oxford: Clarendon, 1987.

17. Johansson S. The adult population's state of health. Stockholm: Fritzes, 1970. [In Swedish].

18. Manor 0, Matthews S, Power C. Dichotomous or categorical response? Analysing self-rated health and lifetime social class. Int J Epidemiol 2000;29:149-57

19. Statistics Sweden. Socioeconomisk indelning (SEI) [Swedish socioeconomic classification]. Stockholm: Statistics Sweden, 1983.

20. Sverke M, Hellgren J. The nature of job insecurity: Understanding employment uncertainty on the brink of a new millennium. Appl Psychol Int Rev 2002:51:23-42.

21. Kinnunen U, Mauno S, Nätti J, et al. Perceived job insecurity: a longitudinal study among Finnish employees. Eur J Work Org Psychol 1999;8:243-60.

22. Mattiasson I, Lingärde F, Nilsson $\mathrm{J}$, et al. Threat of unemployment and cardiovascular risk factors: longitudinal study of quality of sleep and serum cholesterol concentrations in men threatened with redundancy. BMJ 1990; 301:461-6.

23. McLean Parks J, Kidder D, Gallagher D. Fitting square pegs into round holes: mapping the domain of contingent work arrangements onto the psychological contract. J Organ Behav 1998:19:697-730.

24. Wilthagen T, Tros F, van Lieshout $H$. Towards 'flexicurity'? balancing flexibility and security in EU member states. Eur J Soc Secur 2004:6:113-36. 